\title{
Evaluation of Onchocerciasis: A Decade of Post Treatment with Ivermectin in Zainabi and Ririwai Doguwa Local Government Area of Kano State
}

\author{
D. A. Sufi*, Tukur Zainab \\ Department of Biological Science, Bayero University, Kano, Nigeria \\ Email: sufi2020@yahoo.com
}

Received 20 November 2014; accepted 3 December 2014; published 14 January 2015

Copyright (C) 2015 by authors and Scientific Research Publishing Inc.

This work is licensed under the Creative Commons Attribution International License (CC BY). http://creativecommons.org/licenses/by/4.0/

(c) (i) Open Access

\begin{abstract}
Rapid Assessment Method (RAM) were carried out to assess the current situation of Onchocerciasis after repetition of annual community directed distribution of Ivermectin in Zainabi and Ririwai of Doguwa Local Government area of Kano State. Certain manifestations, like nodules, leopard skin and blindness, were used to measure the endemicity level in the community. The subjects of 30 50 years who are engaged in rural occupation, resident in that community, were examined for the presence of nodules, skin lesion and blindness. The common manifestation in both communities is nodules with $3(3.40 \%)$ and $2(3.44 \%)$. Leopard skin and blindness were found in Zainabi with 2 $(2.27 \%)$ and $2(2.27 \%)$. The manifestation of Onchocerciasis was found in older age groups of 49 70 and 50 - 69 respectively, which give an indication that the disease was eliminated in the community due to mass distribution of Ivermectin in the previously known endemic community. We recommend mass distribution of Mectizan in other identified endemic foci.
\end{abstract}

\section{Keywords}

Onchocerciasis, Ivermectin, Onchocerca volvulus, Zainabi, Ririwai

\section{Introduction}

Onchocerciasis or river blindness is a parasitic disease caused by the filarial worm Onchocerca volvulus transmitted by repeated bites of infected blackflies (Simulium damnosum). These blackflies breed in fast-flowing rivers and streams, mostly in remote villages located near fertile land where people rely on agriculture. The adult worms

\footnotetext{
${ }^{*}$ Corresponding author.
}

How to cite this paper: Sufi, D.A. and Zainab, T. (2015) Evaluation of Onchocerciasis: A Decade of Post Treatment with Ivermectin in Zainabi and Ririwai Doguwa Local Government Area of Kano State. Advances in Entomology, 3, 1-5. http://dx.doi.org/10.4236/ae.2015.31001 
produce embryonic larvae microfilariae that migrate to the skin, eyes and other organs in the human body. When a female blackfly bites an infected person during a blood meal, it also ingests microfilariae which develop further in the blackfly and are then transmitted to the next human host during subsequent bites [1]. O. volvulus infection affects an estimated 17.7 million people worldwide in 34 countries of Africa, the Middle East, South America and Central America. An estimated 500,000 people and 270,000 people experience secondary visual impairment and blindness, respectively [2]. Nations with the highest historical prevalence of Onchocerciasis include 11 sub-Saharan West African nations, such as Ghana, Nigeria, Liberia and parts of Mali; however, endemicity extends latitudinal across the entire continent of Africa and into Southwest Asia, with patchy foci in Yemen and Oman in the Arabian Peninsula. Small foci are also located in Ecuador, Venezuela, Colombia, Brazil, southern Mexico and Guatemala [3]. Relationships between infection prevalence and individual infection intensity and between infection prevalence and transmission intensity appear to follow similar patterns in Africa and in Latin America, lending epidemiological support for Mesoamerican O. volvulus having a genetically recent relation to African O. volvulus [4]. All in all, an estimated 123 million people live in areas where the disease is endemic. Onchocerciasis among non immigrant North Americans is almost entirely limited to travelers to areas of endemicity. As a human disease, Onchocerciasis has shown more than just an effect on the quality of life; it also appears to shorten it. [5] found an association between $O$. volvulus microfilarial load and all-cause mortality, claiming that $5 \%$ of the deaths in the study's temporal and regional boundaries were attributable to $O$. volvulus infection. Blindness per se did not appear to have a significant effect on mortality when adjusted for microfilarial load. Recent data show that patients with glaucoma in Ghana have a higher prevalence of onchocerciasis (i.e., they have positive skin snip test results), even after adjustment for age, region and sex [6]. If exposed to HIV, especially the macrophage-tropic HIV-1, patients with Onchocerciasis have a greater likelihood of converting to HIV positivity than those without Onchocerciasis [7]. The same study also suggests that the treatment of Onchocerciasis in HIV-1 infecting patients decreases viral replication. HIV infection may worsen the severity of Onchodermatitis, although this aspect of the relationship has not been well studied [8]. Recent work by [9] reaffirms that it is safe to include HIV-infected patients in mass-treatment populations. Ivermectin (MK-0933, 22, 23-dihydroderivative of Amvermectin B1) is a synthetic derivative of a broad spectrum antiparasitic class of macro cyclic lactones known as avermectins. Avermectin B was first isolated by fermentation of a soil microorganism, the actinomycete Streptomyces avermitilis. Ivermectin has a structure similar to that of macrolide antibiotics, but without antibacterial activity [10]. Ivermectin acts by binding selectively to specific neurotransmitter receptors that function in the peripheral motor synapses of parasites. It has an endectocidal effect (simultaneously against endo and ectoparasites) causing paralysis of nematodes, arthropods and insects by suppressing the conduction of nervous impulses in the interneuronic (intermediary neurons) synapses of nematodes and the nerve-muscle synapses of the arthropods and insects [11]. Ivermectin blocks chemical transmission across the nerve synapses that use glutamate-gated anion channels or $\gamma$-aminobutyric acid-gated chloride channels. Stimulation of $\gamma$-amino-butyric acid (GABA) releasing from presynaptic nerve endings and enhancement of the binding to the postsynaptic receptors accomplishes this [12]. Ivermectin does not affect synapses gated by other transmitter substances, such as acetylcholine, nor epinephrine and serotonin [13]. This leads to an increase in the permeability of the cell membrane to chloride ions with the hyper polarization of the cell, resulting in paralysis and death of the parasite [14]. As Ivermectin continues to be used in both animals and humans, resistance presents another challenge to global eradication efforts [15]. [16] maintained there may not be preexisting resistance genes among $O$. volvulus populations, slowing the development of Ivermectin resistance. However, a study by [17] suggests that the genetic heterogeneity of $O$. volvulus is higher than previously thought. They believe that resistance alleles do preexist, that mass Ivermectin treatment is rapidly transforming the population genetics of $O$. volvulus, and that clinical resistance is imminent. Indeed, parasites from Ivermectin-treated patients demonstrate decreased diversity at many genetic loci for P-glycoprotein [17] and [18]. The aim of the study is to determine the current status of Onchocerciasis in the endemic community after ten years of uninterrupted distribution of Ivermectin drugs.

\section{Materials and Methods}

\subsection{Study Area}

The study was carried out in Zainabi, and Ririwai Doguwa Local Government Area of Kano State. The areas which cover about $717 \mathrm{~km}^{2}$ with population 188,859 [19], at co-ordinates between longitude $8^{\circ} 41.313$ 'E and $8^{\circ} 47.259^{\prime} \mathrm{E}$, between latitude $10^{\circ} 41.74^{\prime} \mathrm{N}$ and $10^{\circ} 49.81^{\prime} \mathrm{N}$. 


\subsection{Ethical Clearance}

Letter of introduction was collected from the Department of Biological Sciences, Bayero University, Kano to Kano State Hospitals Management Board for ethical approval. The approved ethical clearance was collected on 20/04/2012.

\subsection{Clinical Examination}

This involves Rapid Assessment Method (RAM). The RAM method was used for the observation of nodules, leopard skin and blindness was used to assess the endemicity level in the community [20]. The community members were informed to gather at the community Primary Health centre during 2012 Ivermectin distribution. Primary Health centre was selected for assessment. The communities were educated on the purpose of the study through the district head and the clinic health personal before the study commence. The subject Sights, Leopard skin, and Nodules were examines and recorded by the Health workers in the clinic. The subjects who are engaged in rural occupation, resident in that community were examined for the presence of nodules, skin lesion and blindness [21] [22]. The total of 146 subjects that reported to their various assessment centres were examined.

\section{Result}

Zainabi and Ririwai are communities located along River Kano at Ririwai. During the study, Onchocerciasis manifestations were examined using Rapid Assessment Method (RAM). The Onchocerciasis manifestation is found in the older age group 49 - 70 and 50 - 69 respectively where as the younger generation show no symptoms of Onchocerciasis (Table 1). The common manifestation in both communities is nodules with 3 (3.40\%) inZainabi and in Ririwai 2 (3.44\%). Leopard skin and blindness were found only in Zainabi with $2(2.27 \%)$ and $2(2.27 \%)$ (Table 2$)$. The total prevalence recorded in both the study communities is $9(11.36 \%)$ out $146(100 \%)$ subjects examined (Table 3 ).

Table 1. Clinical manifestation of Onchocerciasis among age group in Zainabi, 2012.

\begin{tabular}{|c|c|c|c|c|c|}
\hline \multirow[t]{2}{*}{ Age Range } & \multicolumn{5}{|c|}{ Number, Examined Number and Percentage of the Subjects with Different Manifestation } \\
\hline & & Nodules & Leopard skin & Blindness & Total prevalence \\
\hline $10-19$ & 3 & $0(0.00)$ & $0(0.00)$ & $0(0.00)$ & $0(0.00)$ \\
\hline $20-29$ & 6 & $0(0.00)$ & $0(0.00)$ & $0(0.00)$ & $0(0.00)$ \\
\hline 30 - 39 & 15 & $0(0.00)$ & $0(0.00)$ & $0(0.00)$ & $0(0.00)$ \\
\hline $40-49$ & 22 & $1(1.13)$ & $0(0.00)$ & $0(0.00)$ & $1(1.13)$ \\
\hline $50-59$ & 11 & $0(0.00)$ & $0(0.00)$ & $0(0.00)$ & $0(0.00)$ \\
\hline $60-69$ & 9 & $0(0.00)$ & $1(1.13)$ & $1(1.13)$ & $2(2.26)$ \\
\hline $70-79$ & 14 & $2(2.27)$ & $1(1.13)$ & $1(1.13)$ & $4(4.53)$ \\
\hline 80 - 89 & 6 & $0(0.00)$ & $0(0.00)$ & $0(0.00)$ & $0(0.00)$ \\
\hline 90 - 99 & 2 & $0(0.00)$ & $0(0.00)$ & $0(0.00)$ & $0(0.00)$ \\
\hline Total & 88 & $3(3.40)$ & $2(2.26)$ & $2(2.26)$ & $7(7.92)$ \\
\hline
\end{tabular}

Table 2. Clinical manifestation of Onchocerciasis among age group in Ririwai, 2012.

\begin{tabular}{ccccc}
\hline Age Range & \multicolumn{3}{c}{ Number, Examined Number and Percentage of the Subjects with Different Manifestation } \\
\hline $\mathbf{1 0}-\mathbf{1 9}$ & 4 & Nodules & Leopard skin & Blindness \\
$\mathbf{2 0}-\mathbf{2 9}$ & 14 & $0(0.00)$ & $0(0.00)$ & $0(0.00)$ \\
$\mathbf{3 0}-\mathbf{3 9}$ & 9 & $0(0.00)$ & $0(0.00)$ & $0(0.00)$ \\
$\mathbf{4 0}-\mathbf{4 9}$ & 13 & $0(0.00)$ & $0(0.00)$ & $0(0.00)$ \\
$\mathbf{5 0}-\mathbf{5 9}$ & 8 & $0(0.00)$ & $0(0.00)$ & $0(0.00)$ \\
$\mathbf{6 0}-\mathbf{6 9}$ & 5 & $1(1.72)$ & $0(0.00)$ & $0(0.00)$ \\
$\mathbf{7 0}-\mathbf{7 9}$ & 4 & $1(1.72)$ & $0(0.00)$ & $0(0.00)$ \\
$\mathbf{8 0}-\mathbf{8 9}$ & 2 & $0(0.00)$ & $0(0.00)$ & $0(0.00)$ \\
$\mathbf{9 0}-\mathbf{9 9}$ & 0 & $0(0.00)$ & $0(0.00)$ & $0(0.00)$ \\
Total & 58 & $0(0.00)$ & $0(0.00)$ & $0.00)$ \\
\end{tabular}


Table 3. Onchocerciasis manifestation in the study communities.

\begin{tabular}{cccccccc}
\hline Sampling Area & \multicolumn{7}{c}{ Number, Examined Sex Number and Percentage of the Subjects with Different Manifestation } \\
\hline & & & & Nodules & Leopard skin & Blindness & Total \\
Zainabi & 88 & 66 (male) & 22 (female) & $3(3.40)$ & $2(2.26)$ & $2(2.26)$ & $7(7.92)$ \\
Ririwai & 58 & 47 (male) & 11 (female) & $2(3.44)$ & $0(0.00)$ & $0(0.00)$ & $2(3.44)$ \\
Total & 146 & 113 (male) & $33($ female) & $5(6.84)$ & $2(2.84)$ & $2(2.26)$ & $9(11.36)$ \\
\hline
\end{tabular}

\section{Discussion}

The results showed that the Onchocerciasis manifestation observed in Zainabi and Ririwai agree that both communities were endemic before the initial distribution of Mectizan drugsin the various communities. High prevalence of Nodules was found among aged group in the study site followed by leopard skin and blindness. The data obtained agree with the work of [23], which indicated the effectiveness of the Mectizan being distributed in the community for over ten years and indicate no symptoms in young age group of Zainabi. Itching is also manifestation of Onchocerciasis, among those examined with the disease, but none of the subject complains of itching in the community. Both Male and Female were examined for the blindness where only a Male participant was seen with blindness, those are members of the community that are already blind due to the disease for past forty years when the disease was identified in the study community.

The result obtained from clinical manifestation using RAM showed nodule is below the threshold standard symptomatology which is in agreement with the study of [23] at Zainabi and has achieved set goal by eliminating Onchocerciasis as Public Health Problem (EPHP) and $\geq 20 \%$ by [24]. The results clearly showed that the infection was largely confirmed to the middle and elderly age groups. These groups are usually the most active members of the communities, occupation wise, and have had a long, exposure to fly bites because of their involvement in farming. The peaks prevalence of Onchocerciasis observed between age group 41 - 50 years, agree with previous reports by [25] and [26]. The decline in ages 70 or above may be related to reduce activity in old age. The record obtained from vector control unit of Kano State Hospital Management Board showed that, Mectizan distribution from Primary Health Care Department of Doguwa local area of Kano state have a treatment coverage rate of $88 \%$. Almost all the members of the community have been taking the drug for 10 to 15 years. Most of the members of the community have taken 3 to 4 dosage of the Mectizan drugs. Leopard skin was the most striking dermatological feature found on the skin of the subjects. Intense itching although common in all age groups, but was more pronounced in age group 50 - 69 years. Itching is linked with dead microfilariae. It is expected that this is high in the older group as the microfilariae age and die with age too. It may also be associated with other factors rather than Onchocercal itching even though it occurs in early symptoms of the disease. Visual impairment was reported in 2 subjects in the communities with either onchocercal nodules or leopard skin, suggesting that it may be due to the infection with Onchocerciasis.

\section{Conclusion}

Considering the low Onchocerciasis manifestation recorded in the study area which is below the threshold to be consider, an area is no longer an endemic foci. This achievement was due to mass distribution of Mectizan drugs for more than 15 years. We recommend mass distribution of Mectizan in other identified endemic foci.

\section{References}

[1] World Health Organization (2014) Onchocerciasis. http://www.who.int/mediacentre/factsheets/fs374/en/

[2] World Health Organization (2001) Onchocerciasis (River Blindness). The 10th International American Conference on Onchocerciasis, 76, 205-212.

[3] Thylefors, B. (2004) Eliminating Onchocerciasis as a Public Health Problem. Tropical Medicine \& International Health, 9, A1-A3. http://dx.doi.org/10.1111/j.1365-3156.2004.01226.x

[4] Basanez, M.G., Collins, R.C., Porter, C.H., Little, M.P. and Brandling-Bennett, D. (2002) Transmission Intensity and the Patterns of Onchocerca volvulus Infection in Human Communities. American Journal of Tropical Medicine and Hygiene, 67, 669-679.

[5] Little, M.P., Breitling, L.P., Basanez, M.-G., Alley, E.S. and Boatin, B.A. (2004) Association between Microfilarial 
Load and Excess Mortality in Onchocerciasis: An Epidemiological Study. The Lancet, 363, 1514-1521. http://dx.doi.org/10.1016/S0140-6736(04)16151-5

[6] Egbert, P.R., Jacobson, D.W., Fiadoyor, S., Dadzie, P. and Ellingson, K.D. (2005) Onchocerciasis: A Potential Risk Factor for Glaucoma. British Journal of Ophthalmology, 89, 796-798. http://dx.doi.org/10.1136/bjo.2004.061895

[7] Gopinath, R., Ostrowski, M., Justement, S.J., Fauci, A.S. and Nutman, T.B. (2000) Filarial Infections Increase Susceptibility to Human Imunodeficienciy Virus Infection in Peripheral Blood Mononumclear Cells in Vitro. Journal of Infectious Diseases, 182, 1804-1808. http://dx.doi.org/10.1086/317623.

[8] Kipp, W., Bamuhiiga, J. and Rubaale, T. (2003) Simulium neavei-Transmitted Onchocerciasis: HIV Infection Increases Severity of Onchocercal Skin Disease in a Small Sample of Patients. Transactions of the Royal Society of Tropical Medicine and Hygiene, 97, 310-311. http://dx.doi.org/10.1016/S0035-9203(03)90157-X

[9] Kipp, W., Bamhuhiiga, J., Rubaale, T. and Kabagambe, G. (2005) Adverse Reactions to the Ivermectin Treatment of Onchocerciasis Patients: Does Infection with the Human Immunodeficiency Virus Play a Role? Annals of Tropical Medicine \& Parasitology, 99, 395-402. http://dx.doi.org/10.1179/136485905X36262

[10] Del Guidice, P. and Marty, P. (1999) Ivermectin: A New Therapeutic Weapon in Dermatology? Arch Dermatology, 135, 705-706.

[11] Bennett, D.G. (1986) Clinical Pharmacology of Ivermectin. JAMA, 189, 100-104.

[12] Turner, M.J. and Schaeffer, J.M. (1989) Mode of Action of Ivermectin. In: Campbell, W.C., Ed., Ivermectin and Abamectin, Springer-Verlag, New York, 73-88. http://dx.doi.org/10.1007/978-1-4612-3626-9 5

[13] Burkhart, C.N. and Burkhart, C.G. (1999) Ivermectin: A Few Caveats Are Warranted before Initiating Therapy for Scabies. JAMA Dermatology, 135, 1549-1550. http://dx.doi.org/10.1001/archderm.135.12.1549

[14] Campbell, W.C. (1993) Ivermectin, an Antiparasitic Agent. Medicinal Research Reviews, 13, 61-79. http://dx.doi.org/10.1002/med.2610130103

[15] Grant, W. (2000) What Is the Real Target for Ivermectin Resistance Selection in Onchocerca volvulus? Trends in Parasitology, 16, 458-459. http://dx.doi.org/10.1016/S0169-4758(00)01804-4

[16] Keddie, E.M., Higazi, T., Boakye, D., Merriweather, A., Wooten, M.C. and Unnasch, T.R. (1999) Onchocerca volvulus: Limited Heterogeneity in the Nuclear and Mitochondrial Genomes. Experimental Parasitology, 93, $198-206$. http://dx.doi.org/10.1006/expr.1999.4450

[17] Ardelli, B.F., Guerriero, S.B. and Prichard, R.K. (2005) Genomic Organization and Effects of Ivermectin Selection on Onchocerca volvulus P-Glycoprotein. Molecular and Biochemical Parasitology, 143, 58-66. http://dx.doi.org/10.1016/j.molbiopara.2005.05.006

[18] Eng, J.K. and Prichard, R.K. (2005) A Comparison of Genetic Polymorphism in Populations of Onchocerca volvulus from Untreated- and Ivermectin-Treated Patients. Molecular and Biochemical Parasitology, 142, 193-202. http://dx.doi.org/10.1016/j.molbiopara.2005.01.021

[19] NPC (2006) National Population Commission.

[20] Dadzie, K.Y., Remme, J., De Sole, G., Boaitin, B., Alley, E.S. and Samba, E.M. (1991) Onchocerciasis Control by Large Scale Ivermectin Treatment. The Lancet, 337, 1358-1359. http://dx.doi.org/10.1016/0140-6736(91)93047-D

[21] Ngoumoh, P. and Walsh, J.F. (1993) A Manual for Rapid Epidemiological Mapping of Onchocerciasis (REMO). Vol. 93, WHO TDR/TDF/ONCHO, Geneva, 4.

[22] Abdullahi, Y. and Oyeyi, T.I. (2003) Current Status of Onchocerciasis in Tudun Wada and Doguwa Local Government Area of Kano State. Nigerian Journal of Parasitology, 24, 77-88.

[23] APOC/WHO (1995) Community Directed Treatment with Ivermectin (CDTI): A Practical Guide for Trainers of Community Directed Distributors. WHO, Genera.

[24] WHO (2012) Report. Accelerating Work to Overcome the Global Impact of Neglected Tropical Disease-A Roadmap for Implementation. Vol. 1211, World Health Organization, Geneva.

[25] Onwuliri, C.O.E., Nwoke, B.E.B., Lawal, I.A. and Iwuala, M.O. (1987) Onchocerciasis in Plateau State of Nigeria. II. The Prevalence among Residents along the Assob River Area. Annals of Tropical Medicine and Parasitology, 81, 4952 .

[26] Gemude, E.I. and Dipeolu, O.O. (1983) Onchocerciasis in Benue State of State of Nigeria. Prevalence of the Disease among the Tivs Living in Gwanda Local Government Area. Annals of Tropical Medicine and Parasitology, 77, 513 516. 
Scientific Research Publishing (SCIRP) is one of the largest Open Access journal publishers. It is currently publishing more than 200 open access, online, peer-reviewed journals covering a wide range of academic disciplines. SCIRP serves the worldwide academic communities and contributes to the progress and application of science with its publication.

Other selected journals from SCIRP are listed as below. Submit your manuscript to us via either submit@scirp.org or Online Submission Portal.
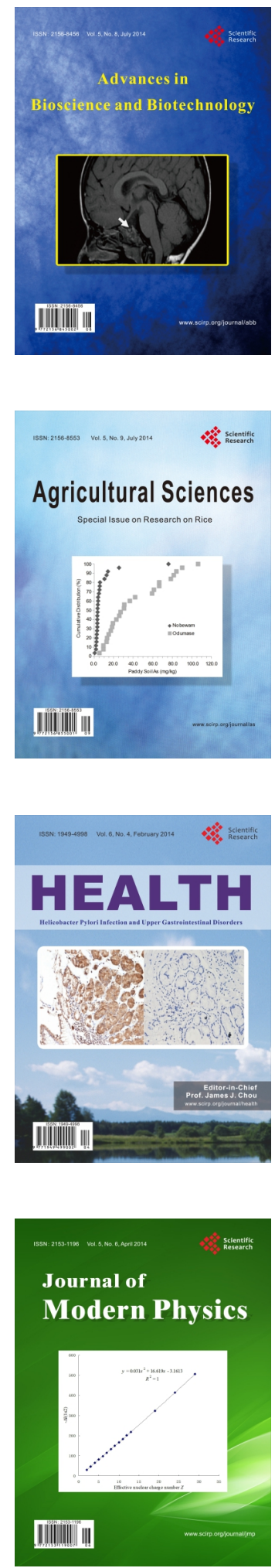
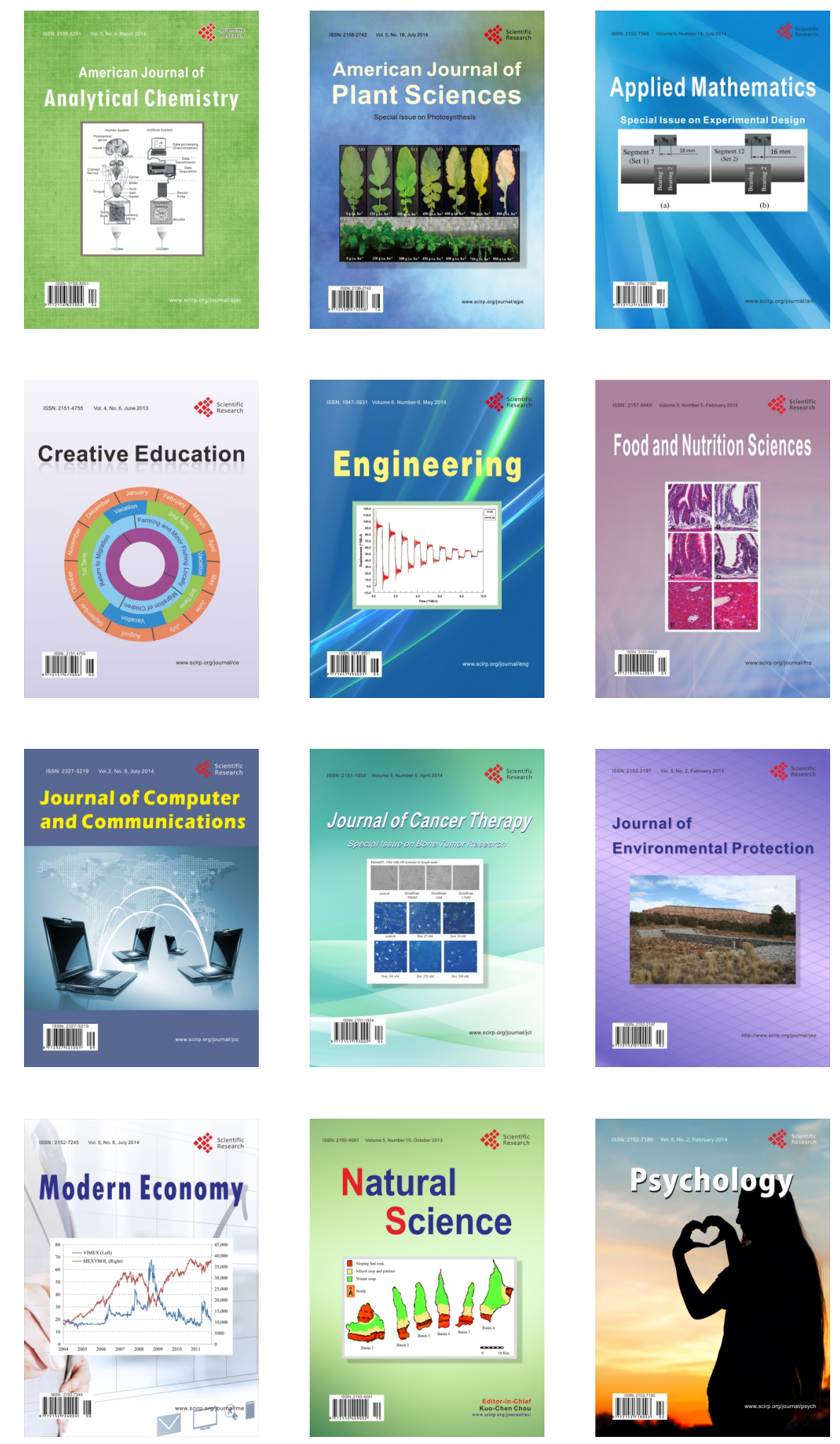